\title{
O passado (também) dura muito tempo ou (re)invenções de um tempo
}

pg 80-90

\section{Resumo}

Este texto configura-se como uma homenagem ao Prof. Fernando Catroga, da Universidade de Coimbra, Portugal. Nele apresento minhas primeiras reflexões sobre "restolho", elemento teórico e metodológico bastante caro às pesquisas desenvolvidas pelo professor homenageado, que nomeio como dispositivo que aciona uma memória e produz diferentes efeitos de sentidos em diferentes espaços de enunciação. A partir de um estudo em dicionários portugueses e brasileiros, explicito os movimentos de sentidos e como eles acompanham as diferentes práticas sociais que temos conhecimento no tocante ao funcionamento da palavra restolho no trabalho de historiadores e de analistas de discurso.

Palavras-chave: Restolho. Prática social. História e memória. Tempo. Discurso.

\section{THE PAST (ALSO) LASTS A LONG TIME OR (RE) INVENTIONS OF A TIME}

\begin{abstract}
The text is a tribute to Prof. Fernando Catroga, from University of Coimbra, Portugal. It presents my first reflections about "stubble", a relevant theoretical and methodological element to the research developed by the honored professor, who I appoint as a device which set a memory and produce different sense effect in different enunciation spaces. Based on a study of Portuguese and Brazilian dictionaries, I explain the movement of meanings and how they follow the different social practices that we have known related to the word "stubble" functioning on the work of historians and discourse analysts.
\end{abstract}

Keywords: Stubble. Social practice. History and Memory. Time. Discourse.

\section{Para Catroga e para mim...}

\author{
"Geme o restolho, triste e solitário \\ a embalar a noite escura e fria \\ e a perder-se no olhar da ventania \\ que canta ao tom do velho campanário"'.
}

Inicio minhas reflexões buscando homenagear Fernando Catroga da forma que imagino que um pesquisador gosta de ser homenageado - sendo lido e tendo seus textos discutidos. Considero, então, Os passos do homem como restolho do tempo (CATROGA, 2009), obra na qual o autor explicita a confirmação de uma certeza que me assola indelevelmente: "a via de acesso ao saber histórico só podia ser aberta pela análise crítica dos traços, vestígios e indícios, voluntária ou involuntariamente deixados pelos homens no restolho do tempo" (CATROGA, 2009, p. 65, grifos do autor). A citação escolhida toca-me muito

1 Professora associada II, DLV/Laboratório Corpus/PPGL/UFSM.

2 A letra da música "Restolho", da cantora portuguesa Mafalda Veiga (1987), funcionará como elo entre as partes do artigo. É pela forma da epígrafe que traçarei uma linha de reflexão que oscila entre o concordar e o discordar. 
especialmente, produzindo sentidos para além do espaço da pesquisa acadêmica, pois traz à baila elementos que me constituem como sujeito do discurso na vida, no mundo. De um lado, está meu interesse em acessar efetivamente o "saber histórico" sobre as línguas e sobre os sujeitos; de outro lado, está meu interesse em acessar elementos "deixados pelos homens no restolho do tempo". É nesse movimento de um lado a outro que vou construir minhas reflexões, não só mobilizando os dizeres de Catroga, mas também resgatando histórias e memórias que fazem de mim o que sou hoje.

Refletir sobre o saber histórico, neste artigo, implicará uma pesquisa em dicionários ${ }^{3}$ portugueses e brasileiros, contrapondo diferentes efeitos de sentidos. Pensar o restolho do tempo permitirá, ao mesmo tempo, falar de Catroga e para ele, e também dizer de mim e para mim que o passado dura muito tempo... Talvez todo o tempo do mundo, se não pela história, a grande 4 , pela memória que é própria a um dado grupo social. As relações entre história e memória talvez sejam a possibilidade mais profícua de caminhar na direção de diferentes práticas sociais, sobretudo do que me proponho a pensar como prática social de tipo novo.

\section{Sobre o saber histórico}

\begin{abstract}
"Geme o restolho, preso de saudade esquecido, enlouquecido, dominado escondido entre as sombras do montado sem forças e sem cor e sem vontade".
\end{abstract}

A noção de "saber histórico" que mobilizo neste trabalho não está ligada ao desejo de ter acesso a ela por uma dada ciência (no sentido positivista do termo) histórica, bem como não faz referência à aspiração de um pesquisador que busque 3 Tenho me ocupado do estudo dos dicionários e dos processos de produção de sentidos nos últimos 12 anos de pesquisa. Trata-se de um objeto discursivo que me interessa muito e sempre.

4 Cf. Henry, 1994. explicações para fatos históricos. Meu objetivo é mobilizar esta noção para explicitar processos de produção de sentidos, em determinados momentos sociais e históricos, que constituam imaginários de portugueses e/ou de brasileiros sobre a língua - ou sobre partes dela.

Concordo com Catroga (2009, p. 106) quando argumenta a favor do estabelecimento de relações entre os historiadores e os filósofos, no sentido de se obter um "convívio proveitoso", o que incitaria uma discussão acerca da "densidade cognitiva e a pertinência das técnicas historiográficas, dentro de um questionamento epistemológico mais amplo sobre as 'relações existentes entre o discurso historiográfico e o referente que ele pretende reconstituir"”. Almejando avançar um pouco mais no terreno profícuo dessas "relações", compreendo não só que a Análise de Discurso pode e deve ser posta em relação à História, sobretudo no que tange às possibilidades de leitura de um dado fato histórico, de uma dada discursividade; mas também podendo servir-se de noções profícuas às análises empreendidas. Isso está dado desde a fundação da Análise de Discurso na França dos anos de 1960, quando houve grande dedicação dos pesquisadores aos estudos epistemológicos.

De fato, Catroga (2009, p. 126) explicita que não há um caráter absoluto ou fechado para a construção do saber histórico, já que uma "dada interpretação (sobretudo se for controversa) terá uma base de convencimento tanto mais ampla quanto mais durável for o reconhecimento do seu maior poder explicativo/compreensivo, em confronto com outras sobre o mesmo objeto". Da mesma forma, o autor indica que a construção do saber histórico se dá pelas relações entre sujeitos, aquele que produz a escrita da história e aquele que lê e atribui sentidos à história, nessas relações que se garante mais ou menos o que o autor chama de "convencimento" ou mesmo de "veracidade" através dos tempos. Em meu entender, é preciso 
ter acesso ao saber histórico para que se produza o conhecimento histórico e, então, se dê o que Catroga chama de "reconhecimento".

A história, para a Análise de Discurso, funciona como constitutiva do sujeito e do sentido e é pela noção de historicidade que aquilo que é exterior à língua passa a significar no discurso. Conforme Orlandi,

[...] trabalhamos continuamente a articulação entre estrutura e acontecimento: nem o exatamente fixado, nem a liberdade em ato. Sujeitos, ao mesmo tempo, à língua e a história, ao estabilizado e ao irrealizado, os homens e os sentidos fazem seus percursos, mantêm a linha, se detêm junto às margens, ultrapassam limites, transbordam, refluem. No discurso, no movimento do simbólico, que não se fecha e que tem na língua e na história sua materialidade. (ORLANDI, 1999, p. 53).

Neste movimento do simbólico do qual fala Orlandi (1999) estão envolvidas diferentes materialidades discursivas em pleno funcionamento e que significam nos e para os sujeitos. Para alcançar o objetivo deste trabalho que é compreender um pouco mais sobre os sentidos de "restolho", me deterei na explicitação de sentidos em diferentes dicionários portugueses e brasileiros, em diferentes momentos sócio históricos, partindo do ano de publicação de 1881 e chegando até o ano de 2009, sem obedecer um rigor cronológico anual ou de decêndio, mas explicitando diferentes momentos históricos, numa sequência cronológica bem ampla, nos dicionários disponíveis ${ }^{5}$ para consulta. Os instrumentos linguísticos selecionados podem ser reagrupados em três blocos: Dicionários 1 e 2, produzidos em Portugal, no final do século XIX; Dicionários 3 e 4, produzidos no Brasil, em meados do século XX; Dicionários 5 e 6 , produzidos no Brasil para plataformas digitais, no início do século XXI, conforme segue:

\section{Dicionário 1}

5 Os dicionários disponíveis para consulta estão no acervo do Laboratório Corpus - UFSM e no acervo pessoal da pesquisadora.
Dicionário contemporâneo de Lingua Portuguesa, de

Caldas Aulete, Portugal, 1881.

Dicionário 2

Novo dicionário da lingua portuguesa, de Cândido de Figueiredo, Portugal, 1899.

\section{Dicionário 3}

Dicionário Prático da Lingua Nacional, de J. Mesquita de Carvalho, Brasil, 1945.

\section{Dicionário 4}

Dicionário da Lingua Portuguesa, de Laudelino Freire, Brasil, 1954.

\section{Dicionário 5}

Dicionário online Caldas Aulete $^{6}$, de Caldas Aulete (direção de Evanildo Bechara), Brasil, 2009.

\section{Dicionário 6}

Dicionário Eletrônico Honaiss da Lingua

Portuguesa, de Antônio Houaiss, Brasil, 2009.

\section{Sobre o restolho e sobre o sujeito}

A palavra "restolho", tal como chegou a mim, pela leitura de Venturini (2017), funcionou como um dispositivo que acionou uma memória guardada em algum lugar importante, mas ainda desconhecido. Restolho, rastolho, rastoio... sonoridades do passado trazidas ao tempo presente. Foi instantâneo! Foi invasivo! Também foi quente como o sol de fevereiro na pele fininha da gente criança, quando caminha, ruidosamente, amassando a palha de uma lavoura de milho recémcolhida. As espigas maduras e bem granadas se foram; ficaram as palhas, as espigas pequenas e com poucos grãos, restos e "restolhos" da produção. Com a palavra restolho vieram também as palavras "resteva" e "respigar", às quais pretendo explorar também neste artigo. Na memória, cenas da infância,

6 Disponível em http://www.aulete.com.br 
um quadro no Museu de Orsay, um trabalho teórico e metodológico sobre o efeito palavra-puxa-palavra (PETRI; SCHERER, 2016) e um deslocamento para refletir sobre como a palavra puxa imagens também. Eis a reprodução da obra de Millet, de 1857, a que faço referência e que ilustra um pouco da relação camponesa com o restolho, a resteva, o respigar?:

Lá se vão mais de 160 anos da produção dessa lavoura recém colhida, da minha infância, para os estudos com a língua, com as discursividades, esboça um pouco do que sou hoje. O início de tudo é um pouco borrado, desfocado, opaco. Buscando alguma explicação para isso: não há! Buscando, ao menos, um conforto para a onda de memórias que me tomou de assalto, lembrei-me da primeira vez que li Proust, na disciplina de Literatura Francesa,

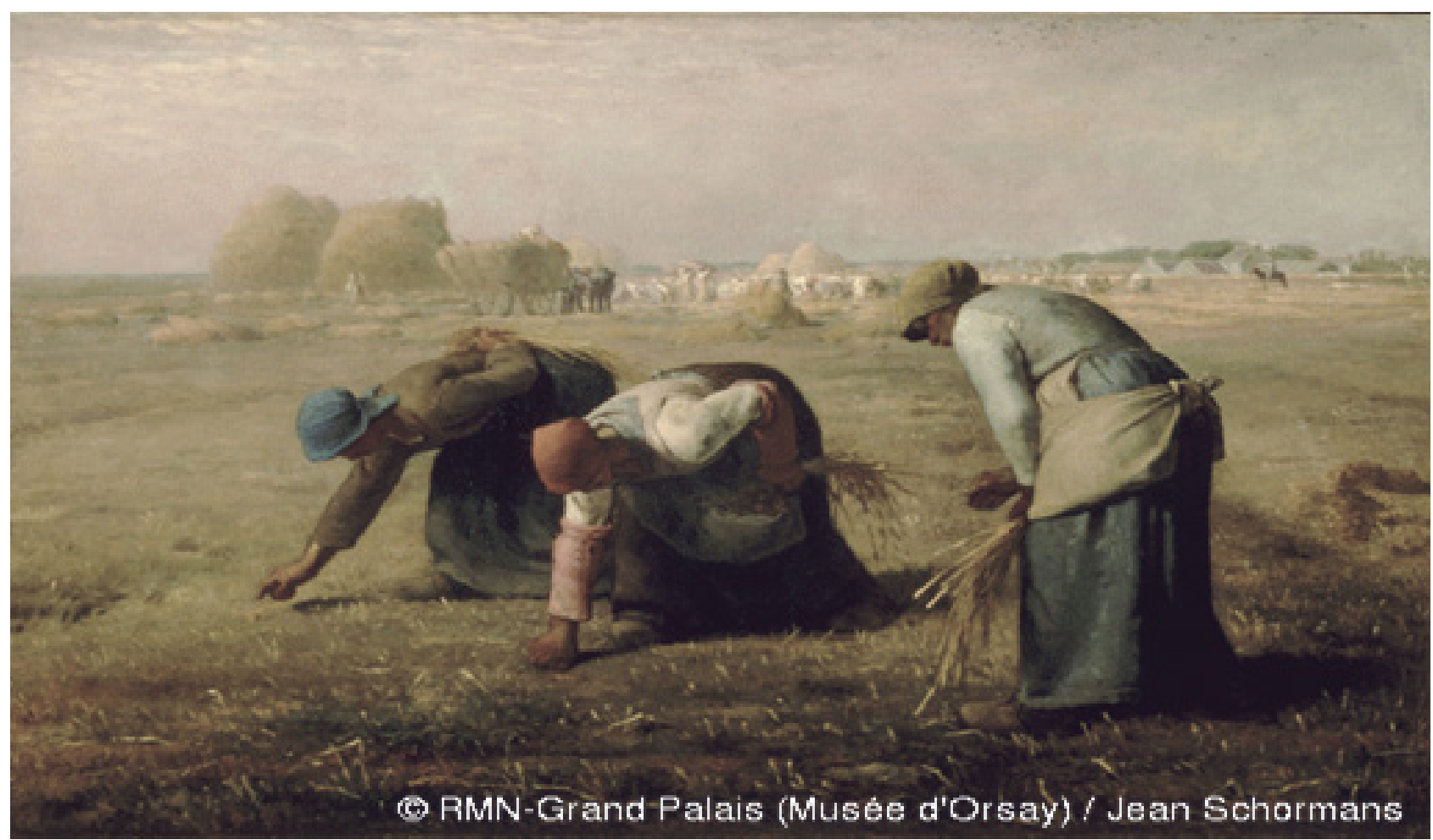

Figura 1: Disponível em: <http://www.musee-orsay.fr/en/collections/works-infocus/search.html?no_cache=1\&zoom=1\&t x_damzoom_pi1\%5BshowUid\%5D=2110>. Acesso em: 02 jan. 2018.

obra de arte, lá se vão mais de 30 anos vividos por esta filha de plantador de grãos, e a cena volta viva: um passado que dura e dura muito em mim. Às vezes tenho a impressão de que eu também "duro" nele - "duro" no sentido de duração no tempo, permanência, e também "duro" no sentido de resistência, como tantos sujeitos que resistem até hoje, produzindo os grãos que matam a fome das multidões. Pelos discursos e pelas possibilidades de sentidos na língua também se alimenta multidões e é nesse lugar que me inscrevo enquanto sujeito de e em práticas sociais. Esse deslocamento da

\footnotetext{
7 Que pode ser conferido nos verbetes dos dicionários apresentados ainda neste texto.
}

ainda na graduação em Letras, no início dos anos 1990, e me emocionei com o episódio da "Madeleine", mergulhada no chá, que se dissolve na boca e aciona memórias de infância. A filha do lavrador lendo Proust em Francês! Ouso dizer que, como o autor, "senti-me menos medíocre, contingente, mortal"- guardadas as devidas proporções. E o sentimento de que o passado também dura muito tempo tomou conta de mim. Naquele tempo, "só" me emocionei, fiz a análise literária solicitada pela professora, mas guardei em mim o que uma sensação pode produzir em um sujeito; hoje compreendo os efeitos da "partilha do sensível" de que nos fala Jacques Rancière. 
Empreender uma reflexão sobre "restolho", e sobre tudo o que ele pode significar é ocupar-se de "ninharias". O analista de discurso ocupa-se de ninharias, explicita elementos que, às vezes, passam despercebidos. Falar de restolho é falar duas vezes em ninharias, pois é assim que a palavra significa duplamente: a) ninharia por ser uma palavra no universo de uma língua; b) ninharia por remeter a restos que ficam para trás. As ninharias também podem durar muito tempo. Este "durar muito tempo" dá conta de certa consciência que se tem do desconhecimento da origem, mas também de que o "para sempre" é uma ilusão. Se, por um lado, a Literatura Francesa me afeta, há um lado da Filosofia e das biografias que há muito vêm me seduzindo, sou sujeito afetado pela leitura da autobiografia (nunca acabada) de Louis Althusser (1992), intitulada O futuro dura muito tempo, vem daí o desejo de intitular este texto e de refletir sobre a duração do tempo para além de uma cronologia qualquer, colocando em relação história e memória: a história de cada um, que é a história de um dado grupo social; a memória que, às vezes, parece perdida e que volta com toda a força a partir de uma sensação (sabor, sonoridade, aroma etc.). Não há como trapacear o tempo e as experiências vividas quando se é interpelado irremediavelmente pela ideologia e se é afetado pelo inconsciente.

Estas experiências vividas e as intertextualidades experimentadas vão formando uma rede e constituindo sentidos em mim. A palavra "restolho" segue por aí produzindo sentidos, fica enchendo a boca de quem a pronuncia, sua sonoridade ressoa em mim e remete à farta (muito antes de se falar em sementes transgênicas) colheita do milho na região de minifúndio agrícola reconhecida como do Alto Uruguai ${ }^{9}$, noroeste do

8 Metáfora utilizada por Vanise Medeiros (2016), em uma apresentação oral, na UNICENTRO/PR.

9 Alto Uruguai é a denominação para uma região fisiográfica do noroeste do Rio Grande do Sul, Brasil. Ela está localizada entre o rio Uruguai e o rio Ijuí e é formada pelos municípios
Rio Grande do Sul, Brasil. Ser criança nesse lugar social era ser guria, era ajudar os pais na labuta diária desde muito pequena, era brincar na terra, conhecer a terra como só o filho e a filha do lavrador conhecem; era ter as mãos sujas de terra e os pés encardidos e isso não ser um problema para ninguém, porque estar impregnado de terra era ser saudável e era estar em sintonia com ela. Aquela realidade transformava o sentido da palavra trabalho, porque trabalho era brincadeira e às vezes a brincadeira era trabalho. $\mathrm{O}$ funcionamento ideológico se revestia de necessidade básica, de subsistência, de empatia dos pequenos com os adultos. Às vezes, os pequenos da casa eram carinhosamente chamados de "restolhos", eles tinham seu valor. Essas memórias não são minhas, são de todo um grupo social que certamente dialoga ou até se assemelha às memórias de outros grupos sociais. Talvez isso não esteja escrito e não tenha o estatuto de conhecimento histórico, mas certamente é um saber histórico passado de pai para filhos desde muito tempo. Produzi esta breve narrativa para ilustrar um pouco do que tenho estudado como "processos de produção de sentido"; mas também para justificar o meu interesse em trabalhar com o restolho, enquanto categoria teórica que me afeta sem cessar.

Para tratar de "restolho" enquanto palavra, enquanto item lexical em funcionamento na língua, neste caso a Língua Portuguesa de Portugal e do Brasil, mais especificamente, refletindo sobre os sentidos que ela pode produzir em diferentes "espaços de enunciação", vou explorar um pouco os dicionários, enquanto instrumentos linguísticos da maior importância nos processos de gramatização das línguas (AUROUX, 1992). Nesse sentido, tomo os dicionários também como "textos que

principais Erechim, Tenente Portela (município onde nasci e vivi até os 17anos), Palmeira das Missões, Sarandi, Santa Rosa, Frederico Westphalen, Getúlio Vargas, Três Passos, Giruá e Três de Maio. Trata-se de uma região bastante agrícola com predominância de minifúndios e lavouras de subsistência. 
se produzem pelo funcionamento da língua nos espaços de enunciação" (GUIMARÃES, 2014, p. 49), sendo que compreendo os espaços de enunciação como "espaços que distribuem desigualmente as línguas para seus falantes, e assim redividem o sensível, ao identificarem os indivíduos ao serem tomados pelas línguas" (GUIMARÃES, 2014, p. 51).

Ao tratar da Língua Portuguesa de Portugal e da Língua Portuguesa do Brasil não me deterei em acordos ortográficos ou em peculiaridades gramaticais de cada uma, estou dando destaque a dois espaços de enunciação bem diferenciados: de um lado, um pesquisador português (e uma cantora portuguesa) produzindo sentidos na e sobre a palavra restolho; de outro lado, um grupo social constituído por lavradores e a sua descendência (agora a pesquisadora que aqui se apresenta), no interior do sul do Brasil, produzindo sentidos sobre a mesma palavra (que já é outra). A distribuição da língua é, sem dúvida, desigual, instaurando pontos em comum (revelando paráfrases) e pontos divergentes (revelando a contradição como constitutiva). Estou diante de uma tensão constitutiva da Língua Portuguesa, uma língua que é muitas e que não cessa de se dividir, ela ressoa, produz ecos bem específicos, sob diferentes condições de produção. Não há um sentido "correto" para a palavra, há sentidos.

Os dicionários são espaços de produção do sujeito na e da língua, sua gramaticalidade, sua ortografia e suas possibilidades de sentidos, mas esses instrumentos não dão conta da totalidade de uma língua e dos efeitos de sentidos que podem ser produzidos. O dicionário, nessa perspectiva, é tomado como objeto discursivo (NUNES, 2006), bem como espaço para se "guardar" a língua imaginária sempre em jogo com a língua fluída (ORLANDI, 2009). De fato, “entendemos que os sentidos são 'aves', eles migram; são 'aves' ariscas, não se deixam aprisionar; são 'aves' que cantam, seu canto ressoa de diferentes maneiras. E, como todas as canções, estas provocam diferentes reações nos sujeitos" (PETRI, 2010, p. 25). Dizer restolho em Portugal, dizer restolho no interior do sul do Brasil; consultar o verbete restolho em dicionários portugueses e em dicionários brasileiros. A isto que me proponho: observar, interpretar, via Análise de Discurso peucheuxtiana, e compreender um pouco mais sobre os processos de produção de sentido em diferentes momentos sócio históricos e em diferentes espaços de enunciação.

Minhas observações e meu gesto interpretativo se dão sobre alguns dicionários, aqueles já mencionados, e com o propósito de explicitar os sentidos para restolho em diferentes instrumentos, diferentes momentos sociais e históricos, mas, sobretudo, em diferentes espaços de enunciação, tendo por base-suporte as condições de produção dos sentidos sobre a palavra em estudo.

\section{Dicionário 1}

\section{O Dicionário contemporâneo de Lingua}

Portuguesa, publicado em Portugal, em 1881, por Caldas Aulete, traz em sua apresentação que foi "feito sobre um plano inteiramente novo". A contemporaneidade, nesse caso, é também tomada no sentido de novidade, o que é reiterado no título da obra. Mais de 130 anos se passaram, o Caldas Aulete tem sua publicação brasileira, agora impressa, sob o mesmo título, e digital sob o título: Caldas Aulete Digital, um site de consulta disponível on line. O verbete estudado é assim apresentado:

Restolho (rres-to-lhu), s. m. a parte inferior do trigo, da cevada e de outras gramíneas, que ficou enraizada na terra depois da ceifa. Restolhal. V. r. Resto. 


\section{Dicionário 2}

O Novo dicionário da língua portuguesa, publicado em Portugal, em 1899, por Cândido de Figueiredo, traz em sua apresentação a justificativa para o título de "novo", pois acrescenta mais de 30 mil vocábulos ao que já estava posto em outros dicionários de Língua Portuguesa produzidos até então. Chama a atenção, em especial, que o autor dá ênfase ao fato de que colheu "na linguagem brasílica, que contribuiu para esta obra com mais de 5.000 vocábulos não registrados até agora em dicionários portugueses", explicitando a presença do português do Brasil em instrumentos linguísticos no final do século XIX ${ }^{10}$. Para o verbete em estudo, ele propõe:

Restolho, s.m. parte inferior do caule das gramíneas, que ficou enraizada depois da ceifa, restolhal; *barulho, o mesmo que restolhada. Cf. G. Braga, Mal da Delf., p. 55. (De resto).

Estes dois primeiros dicionários apresentam noções muito próximas, constituindo uma rede entre dicionários produzidos em um mesmo espaço de enunciação e sob condições de produção muito próximas. Destaque para a referência à palavra resto, que remete a sentidos pejorativos neste período para estes dois dicionários, o que depois vai desaparecer e quando retornar vai deslocar os sentidos inicialmente presentes.

\section{Dicionário 3}

O Dicionário Prático da Língua Nacional, publicado no Brasil, em 1945, por J. Mesquista de Carvalho, propõem, em sua apresentação: o registro dos "vocábulos mais usados na vida moderna" e para que não se tornasse muito externo seriam omitidos "brasileirismos e lusitanismos dispensáveis, os nomes técnicos, senão quando sejam homógrafos verbetes, e os nomes enciclopédicos".
Restolho - s. m. Lat. hip. restunculum. Parte do caule das gramíneas que fica enraizada depois da ceifa. Restolhal. Barulho. Restolhada. COGNATOS: restolhada (s. f. grande quantidade de restolho; ruído produzido pelas pessoas que andam sobre o restolho; ruído, barulho, estrondo); restolhador (s. m. respingador); restolhal (s. $\mathrm{m}$. terreno em que há restolho); restolhar (v. intr.. rebuscar no restolho; procurar os restos; fazer ruído andando sobre ou entre o restolho; fazer bulha ou ruído; v. trans.: respingar; v. trans.-rel. respigar).

No caso deste terceiro dicionário estudado, observa-se que já não há referência explicita ao verbete "resto" como havia nos anteriores, apresentando-se um movimento em direção aos cognatos, sejam eles substantivos, sejam eles verbos.

\section{Dicionário 4}

O Dicionário da Lingua Portuguesa, publicado no Brasil, em 1954, por Laudelino Freire, traz em sua apresentação as características de "grande e novíssimo" Dicionário.

Restolho s. m. Parte inferior do caule das gramíneas que ficou enraizada depois da ceifa. 2 Restolhal. 3 Barulho, o mesmo que restolhada.

Observa-se a repetição de sentidos já postos nos dicionários anteriores, mas já não aparece mais a referência a "resto", tão presente nos dicionários portugueses publicados no final do século XIX. Ao mesmo tempo observa-se que tanto no final do século XIX quanto em meados do século XX há uma forte presença da acepção que nos remete a ruído e barulho, já indicando os sentidos que prevalecem nos estudos da linguagem até o presente momento. Pois o que tem ruído, faz barulho, incomoda e interessa aos pesquisadores que se ocupam das questões da linguagem.

\section{Dicionário 5}

O Dicionário Online Caldas Aulete foi publicado em uma primeira versão simplificada em 2007, 
sendo ampliada para o formato que tem hoje no ano de 2009. Os editores explicam que este dicionário online traz em seu bojo mais de 200 mil verbetes já presentes na primeira versão, ainda em Portugal no final do século XIX (acima citada), bem como acrescenta mais de 80 mil verbetes da atualidade, e com tudo isso, unindo tradição e novas tecnologias, vai "tornar-se o maior banco de dados do idioma." $O$ verbete em estudo assim se apresenta:

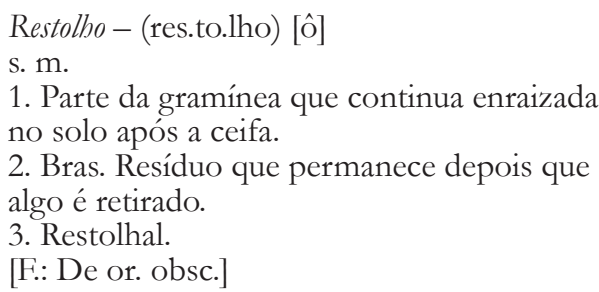

\section{Dicionário 6}

Por último, dicionário bastante atual e bastante consultado no Brasil, o Dicionário Eletrônico Honaiss da Lingua Portuguesa, disponibilizado em 2009, em forma de CD que acompanha a versão impressa, traz informações importantes, dentre as quais, destaca-se o período de aparecimento da palavra e os diversos modos de significar. $\mathrm{O}$ verbete em análise assim se apresenta:

\footnotetext{
Restolho 1188-1230 (origem obscura) substantivo masculino

1 palha que fica no campo após a colheita 2 parte do caule das gramíneas que fica enraizada após a ceifa

3 erva que nasce de novo depois de ceifada 4 Regionalismo: Brasil. resto, depois de tirado o que havia de melhor; conjunto de sobras, de resíduos

5 ruído, barulho
}

Já a forma verbal "restolhar" vai ser datada do século XIX e traz em seu bojo acepções que interessam ao analista de discurso, ao filósofo, ao historiador, conforme segue:

\footnotetext{
Restolhar 1836 (deriva de restolho + ar) verbo transitivo direto e intransitivo 1 catar no restolho, aproveitar o restolho; procurar os restos
}

\author{
Ex.: r. alimentos \\ os miseráveis restolham \\ transitivo direto \\ 2 Derivação: por analogia. \\ catar, procurar de modo minucioso \\ Ex.: r. os erros de um texto \\ intransitivo \\ 3 causar ruído, movendo-se pelo restolho \\ intransitivo \\ 4 Derivação: por extensão de sentido. \\ fazer ruído ou bulha \\ Ex.: animal que vem restolhando
}

Este terceiro bloco de dicionários faz retornar a acepção de resto, mas não mais como algo a ser abandonado, deixado para traz ou com sentido pejorativo, pois o resto aqui vai significar aquilo que ainda resiste, que chama a atenção, que pode interessar ao pesquisador. Da mesma forma, ressalto a presença constante do barulho e do ruído, pois ele não deixa o pesquisador descansar, fica incomodando, demandando discursivização. Cada acontecimento que se dá no âmbito histórico interessa ao historiador e também ao analista de discurso, por menor que seja, é o restolho que nos instiga a seguir pesquisando.

De um lado a força do restolho vinculado aos campos de trigo portugueses de outrora, de outro lado os campos de trigo e milho do sul do Brasil de outrora e de hoje. Diferentes espaços de enunciação, diferentes acontecimentos, diferentes sujeitos vivendo a divisão das línguas e experimentando relações muito peculiares com o restolho. Seja pela generalização dos grandes dicionários, seja pelo lugar dos regionalismos e brasileirismos, o restolho resiste e continua produzindo sentidos.

\section{Por práticas sociais de tipo novo}

"Mas é preciso morrer e nascer de novo
semear no pó e voltar a colher
há que ser trigo, depois ser restolho
há que penar para aprender a viver".

No desejo de colocar um ponto final nesta reflexão, trago à baila os versos de Mafalda Veiga 
em relação à lavoura que tem seu ciclo - e com ele também se vai aprendendo a viver, a assumir posições de sujeito. $\mathrm{O}$ restolho, com seu funcionamento na agricultura desde o século XII, vem funcionar no discurso de historiadores e linguistas, em pleno século XXI. Essa realidade diz muito da história e sobre ela, bem como das relações da história com as questões da linguagem. Em mim, restolho funcionou como um dispositivo de memória, de uma tomada de consciência e de uma retomada de um saber histórico que me constitui. Atualmente, no âmbito das minhas pesquisas, restolho significa também como significa para Catroga (2009) e este artigo propõe-se a colaborar para a compreensão da palavra e de seu funcionamento no discurso e na produção de sentidos.

Assim como ensina Davallon (1999), compreendo que a história resiste mais e melhor ao tempo do que a memória, mesmo uma memória de um dado grupo social que vai se perpetuando pela oralidade, está sempre correndo o risco de desaparecimento, o que não ocorre com a história que tem como princípio a invenção da escrita, tendo desenvolvido estratégias para guardar saberes, tais como documentos, depoimentos, testemunhos, arquivos, acervos, sob a égide da História. É nesse entremeio que observo a construção de um dado saber histórico que pode ou não se tornar um conhecimento histórico. O saber histórico é, para mim, tudo aquilo construído no interior de um dado grupo social (modos de produção no trabalho, lendas, canções, mitos etc.) e que tem seu funcionamento na instância do simbólico, no sentido que Eni Orlandi (1999) empresta ao termo. A colheita do milho, realizada de modo artesanal (sem máquinas) e que já seleciona as melhores espigas para o comércio, introduz a necessidade de uma segunda fase, a do respigar que tantas vezes foi tarefa destinada às mulheres e às crianças. Isso diz muito dos modos de produção de uma dada sociedade organizada. Trata-se do plantio e da colheita realizados pelas próprias mãos do lavrador e de sua família, uma prática social muito antiga, replicada por séculos e que ainda não desapareceu - do cenário brasileiro pelo menos.

Este processo, como um todo, pode não estar na história, a grande, com o estatuto de uma grande revolução ou de uma luta política de repercussão internacional, mas está na memória coletiva e constitui um saber histórico, explicitando um "saber-fazer" constitutivo de um grupo social que se organiza em torno da produção de grãos, seja em Portugal, seja no Brasil, seja em outro lugar. Considero que as práticas sociais, tal como as compreendo, constituem sentidos no e para o sujeito, sendo inarredavelmente históricas, passíveis de discursivização.

Por tudo isso também, a noção de espaço de enunciação é muito importante para esta reflexão, já que as práticas sociais realizam-se efetivamente em um dado espaço de enunciação, significando de modos diversos para diferentes sujeitos, inscritos em diferentes formações discursivas. No espaço de enunciação brasileiro, o restolho significa em pleno século XXI - aquilo que resta, mas que ainda está pleno em grãos, no restolho ainda estão guardadas sementes, ainda que não tenham o mesmo estatuto das grandes espigas. No restolho, tal como é compreendido no sul do Brasil, há um devir, tanto o passado dura muito tempo como o futuro também nos desafia e promete durar muito tempo.

Já no espaço de enunciação português denota-se o sentido de resto da lavoura já ceifada em sua totalidade e há certa nostalgia sobre a palavra que remete à construção de uma memória bem específica, instaurada no interior de um grupo social e respeitada por tantos outros como história de Portugal. No espaço de enunciação português, o restolho tem seu lugar na canção nostálgica de Mafalda Veiga, nos trabalhos da história coordenados por Catroga (e outros), fazendo ecoar sentidos advindos lá na prática social da lavoura, e já 
constituindo uma prática social de tipo novo, na qual o restolho tem sua importância e talvez o "respigar" seja tomado como parte de uma metodologia para fazer a História levando em consideração elementos próprios do discurso, tal como é concebido na/pela Análise de Discurso pecheuxtiana.

Enfim, apresentei algumas reflexões sobre a duração do tempo, da palavra restolho no tempo produzindo efeitos de sentido, ainda falta muita pesquisa para compreender como se constituem as práticas sociais e como elas produzem sentidos em nós.

\section{Referências}

ALTHUSSER, Louis. O futuro dura muito tempo, seguido de Os fatos. Rio de Janeiro: Companhia das Letras, 1992.

AUROUX, Sylvain. A revolução tecnológica da gramatização. Campinas: Editora da. UNICAMP, 1992.

CATROGA, Fernando. Os passos do homem como restolho do tempo. Memória e fim do fim da história. Coimbra: Almedina, 2009.

DAVALLON, Jean. A imagem, uma arte da memória? In: ACHARD, Pierre [et al.]. Papel da memória. Campinas, SP: Pontes, 1999. p. 23-38.

GUIMARÃES, Eduardo. Espaço de enunciação, cena enunciativa, designação. In: Coleção Fragmentum, n. 40. Publicação do Laboratório Corpus, UFSM. Santa Maria, RS: Editora do PPGL, 2014. p. 49-68.

GUIMARÃES, Eduardo. Sinopse dos estudos do português no Brasil: a gramatização brasileira. In: GUIMARÃES, Eduardo; ORLANDI, Eni Puccinelli. (Orgs.) Lingua e cidadania: O Português no Brasil. Campinas: Pontes, 1996.

HENRY, Paul. A história não existe? In: ORLANDI, E. (Org.). Gestos de Leitura - da História no Discurso. Campinas: Editora da Unicamp, 1994.
NUNES, José H. Dicionários no Brasil: análise e história - do século XVI ao XIX. Campinas, SP: Pontes Editores; São Paulo: FAPESP; São José do Rio Preto: FAPERP, 2006.

ORLANDI, Eni. P. Lingua Brasileira e Outras Histórias: discurso sobre a língua e ensino no Brasil. Campinas: Editora RG, 2009.

—. Análise de Discurso: princípios \& procedimentos. Campinas: Pontes, 1999.

PETRI, Verli. Um outro olhar sobre o dicionário: a produção de sentidos. [Verli Petri, com a participação de Daiane Siveris, Daiane da Silva Delevati, Nina Rosa Licht Rodrigues]. Santa Maria: UFSM, PPGL-Editores, 2010.

PETRI, Verli; SCHERER, Amanda. O funcionamento do político na produção de sentidos: o dicionário como trajeto de leitura In:

A análise do discurso e sua história: avanços e perspectivas. Campinas, SP : Pontes Editores, 2016. p. 359-373.

RANCIÈRE, Jacques. A partilha do sensivel: estética e política. São Paulo: EXO Experimental.org; Editora 34, 2005.

VEIGA, Mafalda. Restolho (letra e música). Álbum Pássaros do Sul. Lisboa: Manuel Faria Produtor, 1987.

VENTURINI, Maria Cleci. História, memória e espaço público: diálogo com Fernando Catroga. Conferência proferida para o Grupo de Estudos Linguísticos do Laboratório Corpus - UFSM, dia 06.11.2017. Mimeo.

\section{Dicionários consultados}

AULETE, Caldas. Dicionário contemporâneo de Lingua Portuguesa. Lisboa: Antônio Maria Pereira Editora, 1881.

AULETE, Caldas. Dicionário Online de Lingua Portuguesa, 2009. Disponível em http://www.aulete. com.br 
CARVAlHO, J. Mesquista de. Dicionário Prático da Lingua Nacional. Rio de Janeiro: Editora Globo, 1945.

FIGUEIREDO, Cândido de. Novo dicionário da lingua portuguesa. Lisboa: Livraria Editora Tavares Cardoso e Irmão, 1899.

FREIRE, Laudelino. Dicionário da Lingua Portuguesa. Belo Horizonte: Livraria e Editora José Olympio, 1954.

HOUAISS, Antônio. Dicionário Eletrônico Honaiss da Lingua Portuguesa, 2009, em CD.

Submissão em 20 de dezembro de 2017

Aceito em 10 de janeiro de 2018. 